\title{
Medication prescribing for asthma and COPD: a register-based cross-sectional study in Swedish primary care
}

Paolina Weidinger ${ }^{1,2^{*}}$, J Lars G Nilsson ${ }^{2}$ and Ulf Lindblad ${ }^{1,3}$

\begin{abstract}
Background: There is a gap between prescribed asthma medication and diagnosed asthma in children and adolescents. However, few studies have explored this issue among adults, where asthma medication is also used for the treatment of chronic obstructive pulmonary disease (COPD). The aim of this study was to examine the relationship between prescribing of medications indicated for asthma and COPD and the recorded diagnosis for these conditions.

Method: In a register-based study, individuals prescribed a medication indicated for asthma and COPD during 2004-2005 (Group $A ; n=14$ 101) and patients with diagnoses of asthma or COPD recorded during 2000-2005 (Group B; $n=12$ 328) were identified from primary health care centers in Skaraborg, Sweden. From a 5\% random sample of the medication users $(n=670)$, the written medical records were accessed. Primary outcomes: prevalence of medication and diagnoses, reasons for prescription. Secondary outcomes: type and number of prescribed drugs and performance of peak expiratory flow or spirometry.

Results: Medications indicated for asthma and COPD was prescribed to $5.6 \%$ of the population in primary care $(\mathrm{n}=14$ 101). Among them, an asthma diagnosis was recorded for 5876 individuals (42\%), 1116 (8\%) were diagnosed with COPD and 545 (4\%) had both diagnoses. The remaining 6564 individuals (46\%) were lacking a recorded diagnosis. The gap between diagnosis and medication was present in all age-groups. Medication was used as a diagnostic tool among 30\% of the undiagnosed patients and prescribed off-label for 54\%. Missed recording of ICD-codes for existing asthma or COPD accounted for $16 \%$.

Conclusion: There was a large discrepancy between prescribing of medication and the prevalence of diagnosed asthma and COPD. Consequently, the prevalence of prescriptions of medications indicated for asthma and COPD should not be used to estimate the prevalence of these conditions. Medication was used both as a diagnostic tool and in an off-label manner. Therefore, the prescribing of medications for asthma and COPD does not adhere to national clinical guidelines. More efforts should be made to improve the prescribing of medication indicated for asthma and COPD so that they align with current guidelines.
\end{abstract}

Keywords: Asthma, COPD, Prescribing, Off-label, Guidelines, Cross-sectional study

\footnotetext{
* Correspondence: paolina.weidinger@vgregion.se

'Department of Public Health and Community Medicine/Primary Health

Care, The Sahlgrenska Academy at Gothenburg University, Gothenburg, Sweden

${ }^{2}$ Skaraborg Primary Care Research and Development Unit, Skövde, Sweden

Full list of author information is available at the end of the article
} 


\section{Background}

Asthma and chronic obstructive pulmonary disease (COPD) are respiratory diseases representing a major burden in health care $[1,2]$. The prevalence varies between countries, with an estimated prevalence of $8 \%$ for asthma, and approximately $4-6 \%$ of the adult population having COPD in Sweden $[3,4]$. There are a number of national and international guidelines for the diagnosis and management of asthma and COPD $[2,5,6]$. Asthma medication is approved for use in both asthma and in COPD and for COPD there is also specific treatment, such as anticholinergics for inhalation, not approved for use in asthma [6].

The diagnosis and management of asthma and COPD often stray from guidelines $[7,8]$ leading to both underdiagnosis, misdiagnosis and inappropriate prescribing practices [9-11]. Particularly for children, asthma medication is often prescribed without diagnosed asthma [12-15]. One third of all preschool children experience periods of wheezing [14] and it may not be easy to differentiate asthma from other wheezing disorders. In the absence of objective measurement, asthma medication is often used as diagnostic tool [15]. However, for patients from the age of six years; the diagnosis can be made with reasonable certainty based on objective measurements [3]. Thus the discrepancy between prescribed asthma medication and diagnosed asthma can potentially be reduced from the age of six. However, in the Netherlands, Zuidgeest et al. found that the gap also continues into adolescent age and they conclude that this could be due to factors such as under-diagnosis, off-label prescribing and the use of asthma medications as a diagnostic tool [12]. Few studies have explored the discrepancy between prescribed medication and diagnosed asthma or COPD in adults. In the Netherlands, Lucas et al. [16] found that only $74 \%$ of the prescriptions of inhaled corticosteroids were prescribed to patients actually having asthma or COPD, indicating a discrepancy also between prescribed medication and COPD. The use of prescribed medication as a tool in the diagnostic assessment was shown in a study from Germany [8]. In this study, trial of medication was used in $22 \%$ of the patients with asthma, but among the patients with COPD, the number was only $5 \%$. Trial of medication thus appears to exist in both asthma and COPD, but to a different extent.

Off-label prescribing is common in many diseases $[13,17]$. In such prescribing, a registered medicine is used in a manner not comprised in the license, including the use of drugs in non-approved age-groups (i.e. children), unrecommended doses, formulations or indications [18]. In the US, $40 \%$ of the medications for asthma are prescribed off-label [17]. Even though not recommended, for some diagnoses it may sometimes be clinically appropriate and might reflect innovative clinical practice. However, in a US study, $73 \%$ of the off-label prescriptions had no or little scientific support [18], and were associated with a number of safety, clinical and ethical issues. Published reports thus indicate that there is a gap between prescribed asthma medication and physician-diagnosed asthma among children and adolescents. However, only few studies have explored this discrepancy among adults, where asthma medication is also indicated for the treatment of COPD.

\section{Aim}

The aim of this study was to examine the relationship between prescribing of medications indicated for asthma and COPD and the recorded diagnosis for these conditions.

\section{Methods}

\section{Setting}

The county of Skaraborg, Region Västra Götaland, in southwest Sweden (approximately 260000 inhabitants) has a well established primary health care with 24 primary health care centres (PHC) covering 97\% $(\mathrm{n}=251$ 718) of the population during the time of the study. Since 1998, it is possible to extract information from the computerized medical records collected during patient visits, including diagnostic measurements, prescribed medications and the physicians' written notes. This information has previously been used in register-based studies $[7,19]$.

\section{Study population}

To be able to determine to what extent prescribing was based on diagnoses and if diagnoses correlated to prescribing, two different patient groups, A and B, were selected. To be able to access information only available in the medical records, a random sample was extracted and the medical records were manually examined for these patients.

\section{Group A (selected based on prescribing)}

Data on all individuals with at least one prescription of medication indicated for asthma or COPD issued during 2004-2005. Medications were identified by their respective ATC-codes (Anathomical Therapeutic Chemical classification) [20]. Included drugs were limited to those used in both asthma and COPD; short-acting $\beta_{2}$-adrenergics (SABA; R03AC02 and R03AC03), long-acting $\beta_{2}$-adrenergics (LABA; R03AC12 and R03AC13), inhaled corticosteroids (ICS; R03BA01, R03BA02, R03BA05 and R03BA07), and fixed combinations of long-acting $\beta_{2}$-adrenergics and inhaled corticosteroids (R03AK06 and R03AK07). Drugs exclusively used in COPD belonging to the R03BB group (anticholinergics) were not included. 


\section{Group B (selected based on diagnoses)}

Data on patients with recorded diagnoses of asthma or COPD, during the period of 2000-2005, with at least one subsequent contact during 2004-2005. The ICD-codes are used in Swedish primary care and ICD codes J45 and J44 were used to identify patients with asthma and COPD respectively. The total target population from group $\mathrm{A}$ and B was 18892 individuals.

\section{Random sample}

The random sample of $5 \%(n=945)$ was randomly extracted from Group A and B using a computer-based tool; Statistics Package for Social Sciences (SPSS version 19.0 for $\mathrm{PC}$ ), and then categorized into age-groups. A number of 39 individuals were excluded due to insufficient information in their medical records and 236 individuals due to lack of prescribed medication (originated only from selection-Group B). The final sample for medical record review thus consisted of 670 individuals. A schematic outline of the patient selection is presented in Figure 1.

Regional Ethics Review Board at Gothenburg University (Dnr. 191-07) approved the study protocol.

\section{Analysis}

The primary outcomes were the difference between prevalence of prescribed medication and prevalence of recorded diagnoses, recorded ICD-code or indication based on written note when no ICD-code was given, including symptom-based indications. Secondary outcomes were type of prescribed drug, number of prescriptions and performed peak expiratory flow or spirometry. The random sample was checked for representativeness against the data set of the total selected population concerning variables available in both data sets, such as key demographics and clinical factors, and a close resemblance was found. In the random sample, the patient records were reviewed in detail and reasons for prescription were categorized into:

- Asthma recorded diagnosis: ICD-code of asthma recorded.

- COPD recorded diagnoses: ICD-code of COPD. Patients with both COPD and asthma were included in this group.

- Provisional diagnoses: Diagnosis of asthma or COPD based on written notes in the text part of the medical records.

- Trial of medication: The physician was uncertain about the diagnosis, to be confirmed by response to medication as a part of the diagnostic assessment.

- Off-label: Off-label by indication; the medication was prescribed for other non-recommended indications or there was no information in the medical record of the patient having neither asthma nor COPD. Off-label by age, dosage, duration of time or route of administration were not considered.



Figure 1 Schematic outline of the patient selection in the study. 
A prescription issued in Sweden is valid for one year, and for long-term medication, prescriptions are commonly issued for the entire year of treatment. SABA used during post-bronchodilator spirometry is provided by the care-giver and are not prescribed to the patient for this occasion.

\section{Statistical methods}

Descriptive statistics were performed using Statistics Package for Social Sciences (SPSS version 19.0 for PC). The data was presented as absolute numbers and percentages and the statistical significance of differences between groups were assessed using chi-squared tests with a significance threshold of $\mathrm{p}<0.05$. All tests were two-sided.

\section{Results}

Characteristics of the population in Skaraborg, the selected population from the PHCs and the random sample is presented in Table 1.

During 2004-2005 medication indicated for asthma and COPD were prescribed to $5.6 \%$ (Group A; $n=14$ 101) of the individuals in Skaraborg primary care. Within this population of medication users, an asthma diagnosis was recorded for 5876 individuals (42\%), 1116 (8\%) were diagnosed with COPD and 545 (4\%) with both COPD and asthma. The remaining 6564 individuals (46\%) were lacking a recorded ICD-code for any of the diagnoses.

The results from Group B demonstrated that an asthma diagnosis was recorded for totally 9296 individuals, 2288 had COPD and 744 had both asthma and COPD. Prescription of medication were lacking among 3420 of the individuals with asthma (37\%), 1172 with COPD (51\%) and among 199 with both asthma and COPD (27\%). The prevalence of asthma and COPD based solely on recorded diagnosis was for the Skaraborg population 3.6\% and 1.2\%

Table 1 Characteristics of the population in Skaraborg, the selected population with medication or diagnoses in primary care, and the random sample

\begin{tabular}{|c|c|c|c|c|}
\hline & & Group A & Group B & \\
\hline & $\begin{array}{l}\text { Skaraborg } \\
\text { population }\end{array}$ & $\begin{array}{l}\text { Medication } \\
\text { users }\end{array}$ & $\begin{array}{c}\text { Asthma or COPD } \\
\text { diagnoses }\end{array}$ & $\begin{array}{l}\text { Random } \\
\text { sample }\end{array}$ \\
\hline & $n=255382$ & $n=14101$ & $n=12328$ & $n=670$ \\
\hline & n (\%) & n (\%) & n (\%) & n (\%) \\
\hline Gender & & & & \\
\hline Male & $127470(50)$ & $5970(42)$ & $5527(45)$ & $295(44)$ \\
\hline Female & $127912(50)$ & 8131 (58) & 6801 (55) & $375(56)$ \\
\hline Age (y) & & & & \\
\hline $0-17$ & $54536(21)$ & 2118 (15) & $2103(17)$ & $100(15)$ \\
\hline $18-70$ & $166315(65)$ & 9488 (67) & $7420(60)$ & $452(68)$ \\
\hline$\geq 71$ & 34531 (14) & 2495 (18) & 2805 (23) & 118 (18) \\
\hline
\end{tabular}

Note; Groups A and B are not mutually exclusive. respectively. The lack of congruence between medication users and individuals with a recorded diagnosis of asthma or COPD is presented graphically in a Venn diagram in Figure 2.

The prevalence of medication in relation to the prevalence of recorded diagnoses, in different age-groups is presented in Figure 3. Lower rate of diagnoses than prescriptions was apparent in all age-groups. Prevalence of medication use was lowest among the youngest patients and increased with age. The average discrepancy (calculated as a weighted mean) between medication prescribing and diagnosis was 2.5 percentage points.

\section{Random sample}

The random sample comprised of 670 individuals. The detailed analysis is presented in Tables 2 and 3. Records of diagnoses were found for 391 of 670 patients (58\%), 320 with asthma and 71 with COPD. In total, 279 patients (42\%) therefore lacked a recommended diagnosis for prescribing of medication. However, among these individuals 44 (16\%) had a provisional diagnosis (asthma or COPD based on doctor's written notes). Among the remaining individuals, 85 (30\%) were prescribed medication on trial as a part of the diagnostic assessment and 150 (54\%) individuals were prescribed off-label. Although there appeared to be differences in prescribing by sex, a chi-squared test to assess differences in prescribing between men and women was not statistically significant $(\mathrm{p}=0.061)$. The most common indications for off-label prescribing were diagnoses of cough $(n=18 ; 12 \%)$ and acute bronchitis $(\mathrm{n}=16 ; 11 \%)$ or symptoms of cough, airway obstruction and dyspnoea $(n=21 ; 14 \%)$.

Among patients with asthma, 135 (42\%) were issued a medication once during 2004-2005 and 117 (37\%) patients were issued medication twice (Table 3). Three or more medications were prescribed amongst 33 out of 71 (46\%) patients with COPD. Among individuals prescribed medication off-label, SABA as the only medication was most common as compared to the rest of the medication users $(95 ; 63 \%, \mathrm{p}<0.001)$. Table 3 also shows that patients with asthma or COPD diagnoses had a higher rate of prescribing than those without recorded diagnoses. Low levels of PEF and spirometry are shown in Table 3.

\section{Discussion}

This is an extensive survey of drug prescribing among a large broadly representative group of patients and based on individual patient records. Our study indicate that medication indicated for asthma and COPD seems to be both over- and under-used; over-used when only half of the medication users actually had one of the recommended diagnoses of asthma or COPD recorded. Underused when individuals having asthma or COPD were lacking prescriptions of medication. We also show that 


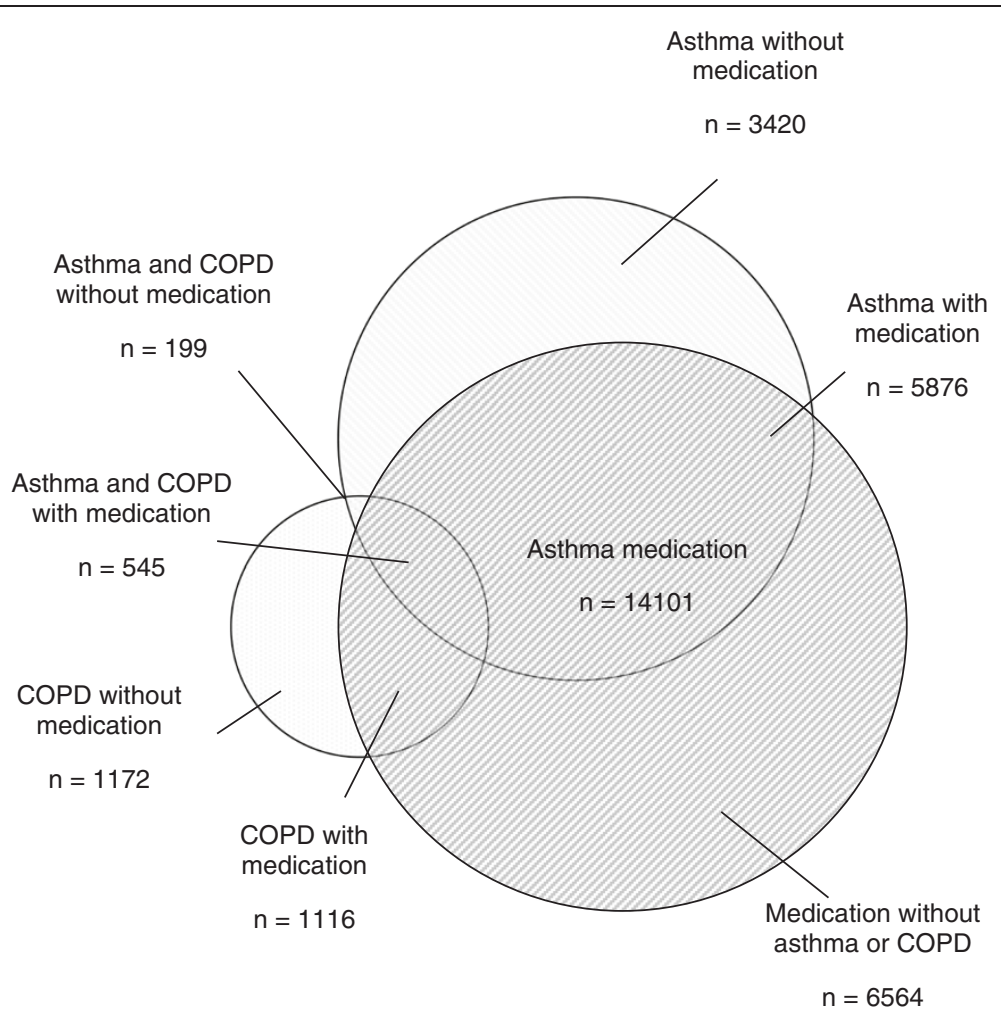

Figure 2 Proportional Venn-diagram of the medication users and their recorded diagnoses.

the use of asthma medication as a diagnostic tool and off-label prescribing were common. Our results are of interest when auditing prescribing in general practice. It should also be observed by researchers in the field studying the epidemiology of asthma and COPD medication use, as discussed below.

The Venn diagram in Figure 2, shows prescribing of medication in relation to diagnoses of asthma or COPD. The figure illustrates the discrepancy between the prevalence of asthma and COPD and the prescribing of medication indicated for these conditions. A considerable proportion of the individuals with asthma or COPD did not have any medication prescribed during the study period, which likely indicates under-medication $[9,21]$. It could also be due to previous incorrect diagnoses of asthma or COPD of individuals not having the recorded disease [22,23]. For COPD it could also be due to exclusive prescribing of anticholinergics (specific only for COPD), without simultaneous prescribing of SABA, LABA or ICS. Approximately half of the individuals

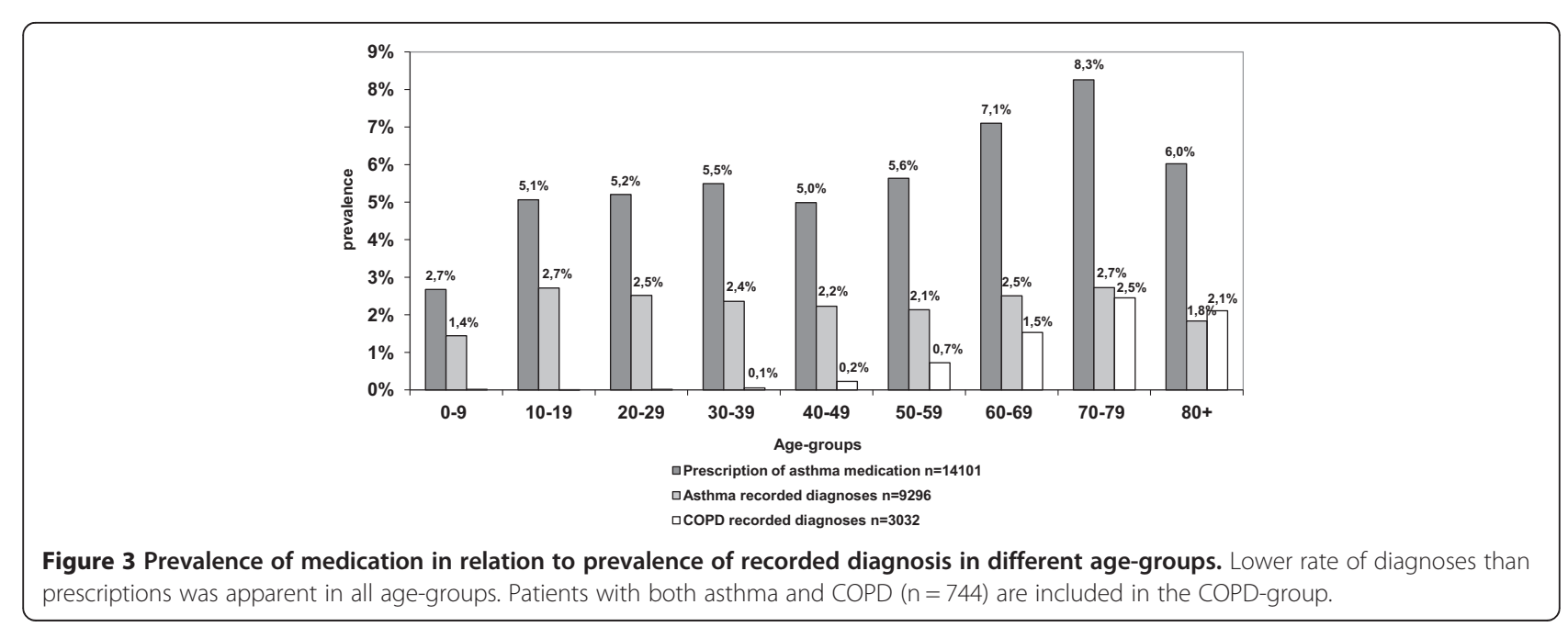


Table 2 Demographic characteristics of subjects in the random sample stratified by recorded asthma or COPD diagnosis, provisional diagnoses, trial by medication and off-label prescribing

\begin{tabular}{|c|c|c|c|c|c|c|}
\hline Treatment & $\begin{array}{c}\text { Total } \\
\mathbf{n}\end{array}$ & $\begin{array}{c}\text { Recorded asthma } \\
\text { diagnosis } \\
\text { n (\%) }\end{array}$ & $\begin{array}{c}\text { Recorded COPD } \\
\text { diagnosis } \\
n(\%)\end{array}$ & $\begin{array}{c}\text { Provisional } \\
\text { diagnoses } \\
\mathrm{n}(\%)\end{array}$ & $\begin{array}{c}\text { Trial by } \\
\text { medication } \\
n(\%)\end{array}$ & $\begin{array}{c}\text { Off-label } \\
\text { prescribing } \\
\text { n (\%) }\end{array}$ \\
\hline All patients & 670 & $320(48)$ & $71(11)$ & $44(7)$ & $85(13)$ & $150(22)$ \\
\hline \multicolumn{7}{|l|}{ Gender } \\
\hline Male & 295 & $140(44)$ & $36(51)$ & $24(55)$ & $39(46)$ & $56(37)$ \\
\hline Female & 375 & $180(56)$ & $35(49)$ & $20(45)$ & $46(54)$ & $94(63)$ \\
\hline \multicolumn{7}{|l|}{ Age groups } \\
\hline $0-17$ & 100 & 59 (18) & & $8(18)$ & $11(13)$ & $22(15)$ \\
\hline $18-70$ & 452 & $223(70)$ & $41(58)$ & $27(61)$ & $58(68)$ & $103(69)$ \\
\hline$\geq 71$ & 118 & $38(12)$ & $30(42)$ & $9(20)$ & 16 (19) & $25(17)$ \\
\hline
\end{tabular}

prescribed a medication had neither a diagnosis of asthma nor of COPD recorded, which probably indicate overmedication (i.e. off-label prescribing) $[13,17,24]$. It could also be due to under-diagnosis of asthma or COPD $[10,11]$, which is supported by the low prevalence figures of $3.6 \%$ and $1.2 \%$, as compared to the national prevalence of $8 \%$ and $4 \%$, respectively [25]. Similar figures have previously been reported from other regions of the Swedish primary care [26].

We have shown that the gap between asthma medication and recorded diagnoses, previously shown mostly in children and adolescents [12,13], exists in all age-groups (Figure 3). The average prevalence of medication use was $5.6 \%$, in line with previous findings $[12,21]$. However, we found that there are fewer children using asthma medication, as compared to the results by Zuidgeest et al. [12] and a decrease in volume of prescribing in the elderly population, which runs counter to the findings of another Swedish study [21]. These differences could be due to inclusion of anticholinergics included in the total volume of drugs in this age-group, in the study by Haupt et al. [21]. It could also be due to hospital doctors' prescribing medication for both the oldest and the youngest, which are not shown in data from primary care [27], and therefore could be interpreted as an absence of medication.

The detailed examination of patient records in the random sample showed that more than half of the undiagnosed medication users (54\%) had the medication

Table 3 Random sample; number of prescriptions, therapy groups and clinical evaluation

\begin{tabular}{|c|c|c|c|c|c|c|}
\hline Treatment & $\begin{array}{c}\text { Total } \\
\mathbf{n} \\
\end{array}$ & $\begin{array}{c}\text { Recorded asthma } \\
\text { diagnosis } \\
\text { n (\%) }\end{array}$ & $\begin{array}{c}\text { Recorded COPD } \\
\text { diagnosis } \\
\mathrm{n}(\%) \\
\end{array}$ & $\begin{array}{c}\text { Provisional } \\
\text { diagnoses } \\
\mathrm{n}(\%) \\
\end{array}$ & $\begin{array}{c}\text { Trial by } \\
\text { medication } \\
\mathrm{n}(\%)\end{array}$ & $\begin{array}{c}\text { Off-label } \\
\text { prescribing } \\
\mathrm{n}(\%) \\
\end{array}$ \\
\hline All patients & 670 & $320(48)$ & $71(11)$ & $44(7)$ & $85(13)$ & $150(22)$ \\
\hline \multicolumn{7}{|l|}{ Number of prescriptions $^{1}$} \\
\hline 1 prescription & 332 & $135(42)$ & $22(31)$ & $25(57)$ & $34(40)$ & $116(77)$ \\
\hline 2 prescriptions & 196 & $117(37)$ & $16(23)$ & $15(34)$ & $26(31)$ & $22(15)$ \\
\hline$\geq 3$ prescriptions & 142 & $68(21)$ & $33(46)$ & $4(9)$ & $25(29)$ & $12(8)$ \\
\hline \multicolumn{7}{|l|}{ Therapy groups ${ }^{2}$} \\
\hline SABA only & 207 & $54(17)$ & $15(21)$ & $14(32)$ & $29(34)$ & $95(63)$ \\
\hline ICS and SABA & 141 & $83(26)$ & $7(10)$ & $13(30)$ & $24(28)$ & $14(9)$ \\
\hline ICS and LABA & 91 & $55(17)$ & $12(17)$ & $7(16)$ & $6(7)$ & $11(7)$ \\
\hline Fixed combination of ICS/LABA & 175 & $102(32)$ & $34(48)$ & $8(18)$ & $17(20)$ & $14(9)$ \\
\hline ICS only ${ }^{3}$ & 56 & $26(8)$ & $3(4)$ & $2(5)$ & $9(11)$ & $16(11)$ \\
\hline \multicolumn{7}{|l|}{ Clinical evaluation } \\
\hline $\mathrm{PEF}^{4}$ only & 36 & $25(8)$ & $1(1)$ & $1(2)$ & $2(2)$ & $7(5)$ \\
\hline Spirometry & 207 & 110 (34) & 37 (52) & $16(36)$ & $24(28)$ & $20(13)$ \\
\hline
\end{tabular}

${ }^{1}$ Number of prescriptions $=$ number of occasions where the patient had one or more medications prescribed.

${ }^{2}$ Therapy groups according to the treatment steps in the therapy recommendations, SABA = Short acting $\beta_{2}$-agonists; LABA = Long-acting $\beta_{2}$ - agonists; ICS = Inhaled Corticosteroids.

${ }^{3}$ ICS is not recommended as monotherapy.

${ }^{4} \mathrm{PEF}=$ Peak Expiratory Flow. 
prescribed off-label. Many previous studies have been performed concerning off-label prescribing among children [24]. Our study shows that off-label prescribing of asthma medication also is common among adults, and used to treat patients with diagnoses of acute bronchitis and cough. Similar findings were reported for $\beta_{2}$-adrenergics for acute bronchitis [28]. Even though the Cochrane group found no evidence for such prescribing [29]; the practice exists, suggesting lack of adherence to evidence based prescribing. The use of medication off-label may be a waste of resources in health care. Moreover, asthma medication represents the most frequently reported cause of adverse reactions among children and adolescents, since half of them were prescribed off-label [30]. Therefore the practice also could constitute a risk for these patients.

We found that asthma medication was often used as a part of the diagnostic assessment (30\%) and 16\% of the individuals, had provisional diagnoses of asthma or COPD, i.e. asthma or COPD based on doctor's written notes and no ICD-code recorded (Table 3). Low levels of PEF and spirometry are shown in Table 3, similar results are reported in our previous study [7], indicating low adherence to guidelines. Among the individuals where the medication was used as a part of the diagnostic assessment, the trial of medication may have been used for diagnosis rather than peak expiratory flow measurement or spirometry, as also reported elsewhere [8].

Among patients with asthma, $79 \%$ were issued a medication once or twice during the two-year period (Table 3). When also considering those with no prescriptions, we conclude that many patients may be inadequately treated, which has also been shown in other studies $[9,10]$. For patients with COPD, the situation was different. They had more prescriptions issued (Table 3) and they contributed extensively to the total population of asthma medication users in the older age-groups (Figure 3). Assuming one year's supply for each prescription (which is common in Sweden) our findings suggest over-medication among patients with COPD, since approximately half of the patients were prescribed three or more medications during the two-year period (Table 3). However, since under-detection of COPD is common [11], the patients detected and diagnosed may be those with more severe COPD and therefore in need of more medication. This interpretation is further supported by the more common use of LABA and fixed combination of LABA/ICS among these patients, and the fact that these medications are to be used in the moderate to severe stages of COPD [6].

Among the 71 patients with COPD, only 37 (52\%) had spirometry performed. Related data from USA and Denmark show similar levels [31,32], which has also been reported in our previous study [7]. This is a clear shortfall in the diagnosis of COPD and a lack of clinical resource and training may be a liable factor in this case. However, access to spirometry equipment was reported by $95 \%$ of the primary health care centers in the same region during the time of the study [33] and the low levels of spirometry found in the present study are to be explained by other factors than availability of spirometry. Against this background of deficiencies in objective diagnostic measures, a trial of medication to help diagnose asthma and COPD appears to be widespread practice.

The use of asthma medication as a proxy for disease prevalence is an on-going debate. Our study confirms previous results of incongruenty between prescription and diagnosis. In the Netherlands, using data from primary care, a single prescription of asthma medication could identify $95 \%$ of adult asthma patients but at the same time $30 \%$ of all asthma medication users with a single prescription were non-asthma patients [34]. On the other hand, several studies have shown a close resemblance between prevalence of medication and prevalence of disease [10,21]. However, in these studies the use of non-linked data sets and the lack of information about diagnoses in databases with dispensed medication are limitations. Our study indicates that the prevalence of asthma and COPD cannot be reliably estimated from the prevalence of prescribing of medication indicated for either of the conditions.

\section{Strengths and limitations of the study}

The data we used had good coverage (97\%) of the population of Skaraborg. This along with the large sample size, are some of the strengths of our study. The sample size for detailed examination of patient records, was restricted for practical reasons $(n=670)$. However, the characteristics of our random sample were similar to the whole population of Skaraborg (Table 1) and therefore likely to be representative for the region. Moreover, the manual examination of the information in the free text field of patient records is an important strength in our study. The sample size was not based on a formal power calculation, but rather chosen considering conclusive findings in previous studies of comparable size $[8,10]$. When using data from routine care, there is a risk that the information about diagnoses and medication has not been documented or appropriately coded in the patients' records. However, due to the detailed examination of the free text field, this risk should be reduced. In this study we were limited to data from primary care. Data from additional caregivers (such as hospital doctors) managing the patient and prescribing medicines are not included, which could be interpreted as an absence of medication. Also we did not have data on pharmacy dispensing or medication compliance. In both cases there is a risk of overestimation of drug use. Treatment by anticholinergics exclusively used in COPD was not included, which could underestimate the total medication use among the patients with 
COPD. Our evaluation of off-label medication use is limited by indication. We did not examine off-label prescribing by age, dosage, duration, or route of administration.

\section{Conclusion}

There was a large discrepancy between prescribing of medication and the prevalence of diagnosed asthma and COPD. Consequently, the prevalence of prescriptions of medications indicated for asthma and COPD should not be used to estimate the prevalence of these conditions. Asthma medication was often prescribed outside recommendations and used both as a diagnostic tool and in an off-label manner. Therefore, the prescribing of medications for asthma and COPD currently does not adhere to national clinical guidelines. More efforts should be made to improve the prescribing of medication indicated for asthma and COPD so that they align with current guidelines. We recommend that the prescribing of these medications and the medical management of both asthma and COPD are regularly audited to improve the prescribing practices in Skaraborg.

\section{Competing interests}

We have no conflicts of interest to declare.

\section{Authors' contributions}

PW coordinated data collection and analysis, wrote the first draft of the paper and prepared the manuscript for publication. JLGN contributed to revisions of the paper and writing the discussion. UL supervised data collection and contributed to revisions of the paper. All authors read and approved the final manuscript.

\section{Acknowledgement}

This study was supported by funds from the Research and Development Unit in Skaraborg Primary Care and the Skaraborg Institute.

\section{Author details \\ ${ }^{1}$ Department of Public Health and Community Medicine/Primary Health Care, The Sahlgrenska Academy at Gothenburg University, Gothenburg, Sweden. ${ }^{2}$ Skaraborg Primary Care Research and Development Unit, Skövde, Sweden. ${ }^{3}$ Skaraborg Institute, Skövde, Sweden.}

Received: 20 August 2013 Accepted: 20 March 2014 Published: 25 March 2014

\section{References}

1. World Health Organization: The World Health Report [database on the Internet]. 2002. Available from: http://www.who.int/whr/2002/en (accessed November 6, 2012).

2. Peters SP, Ferguson G, Deniz Y, Reisner C: Uncontrolled asthma: a review of the prevalence, disease burden and options for treatment. Respir Med 2006, 100(7):1139-1151.

3. Global Initiative for Asthma: Global strategy for asthma management and prevention. Guidelines available from the GINA website. http://www. ginasthma.com (accessed November 6, 2012).

4. Lundbäck B, Gulsvik A, Albers M, Bakke P, Rönmark E, van der Boom G, Brøgger J, Larsson LG, Welle I, van Weel C, Omenaas E: Epidemiological aspects and early detection of chronic obstructive airway diseases in the elderly. Eur Respir J 2003, 21(40):3s-9s.

5. Global Initiative for Chronic Obstructive Lung Disease: Global Strategy for the Diagnosis, Management and Prevention of COPD. Guidelines available from the GOLD. website http://www.goldcopd.org (accessed November 6, 2012).
6. National Board of Health and Wellfare: The National Board of Health and Wellfare Guidelines for Asthma and COPD 2004 (in Swedish). Stockholm, Sweden: Socialstyrelsen; 2004

7. Weidinger $P$, Nilsson JLG, Lindblad U: Adherence to diagnostic guidelines and quality indicators in asthma and COPD in Swedish primary care. Pharmcoepidemiol Drug Safe 2009, 18(5):393-400.

8. Schneider A, Gantner L, Maag I, Borst MM, Wensing M, Szecsenvi J: Are ICD-10 codes appropriate for performance assessment in asthma and COPD in general practice? Results of a cross sectional observational study. BMC Health Serv Res 2005, 5(1):11.

9. Nolte $H$, Nepper-Christensen, Backer V: Unawareness and undertreatment of asthma and allergic rhinitis in a general population. Respir Med 2006 100(2):354-362

10. Hasselgren M, Arne M, Lindahl A, Janson S, Lundbäck B: Estimated prevalence of respiratory symptoms, asthma and chronic obstructive pulmonary disease related to detection rate in primary health care. Scand J Prim Health Care 2001, 19(1):54-57.

11. Lindberg $A$, Jonsson AC, Rönmark E, Lundgren R, Larsson LG, Lundbäck B Prevalence of Chronic Obstructive Pulmonary Disease according to BTS, ERS, GOLD and ATS criteria in relation to doctor's diagnosis, symptoms, age, gender, and smoking habits. Respiration 2005, 72(5):471-479

12. Zuidgeest MG, van Dijk L, Smit HA, van der Wouden JC, Brunekreef B, Leufkens HG, Bracke M: Prescription of respiratory medication without an asthma diagnosis in children: a population based study. BMC Health Serv Res 2008, 8:16.

13. Baiardi P, Ceci A, Felisi M, Cantarutti L, Girotto S, Sturkenboom M, Baraldi E: In-label and off-label use of respiratory drugs in the Italian paediatric population. Acta Paediatr 2010, 99(4):544-549.

14. Bisgaard H, Szefler S: Prevalence of asthma-like symptoms in young children. Peadiatr Pulmonol 2007, 42(8):723-728.

15. Koster ES, Wijga AH, Zuidgeest M, Belitser SV, Raaijmakers JA, Koppelman GH, Postma DS, Brunekreef B, de Jongste JC, der Zee AH M-v: Patterns of medication use: early asthma therapy initiation and asthma outcomes at age 8. Pharmacoepidemiol Drug Safe 2010, 19(10):991-999.

16. Lucas AEM, Smenk FWJ, Smeele I, van Schayck CP: Overtreatment with inhaled corticosteroids and diagnsotic problems in primary care patients, an exploratory study. Fam Pract 2008, 25:86-91.

17. Radley DC, Finkelstein SN, Stafford RS: Off-label Prescribing Among Office-Based Physicians. Arch Intern Med 2006, 166(9):1021-1026.

18. Gazarian M, Kelly M, McPhee JR, Graudins LV, Ward RL, Campbell TJ: Off-label use of medicines: consensus recommendations for evaluating appropriateness. MJA 2006, 185(10):544-548.

19. Hjerpe P, Merlo J, Ohlsson H, Bengtsson Boström K, Lindblad U: Validity of registration of $I C D$-codes and prescriptions in a research database in Swedish primary care: a cross-sectional study in Skaraborg primary care database. BMC Med Inform Decis Mak 2010, 10:23.

20. Guidelines for ATC classification and DDD assignment 2006. Oslo, Norway: WHO Collaborating Centre for Drug Statistics Methodology; 2006. Available at http://www.whocc.no (accessed November 6, 2012).

21. Haupt D, Wettermark B, Nilsson JLG: Dispensed volumes of anti-asthmatic drugs related to the prevalence of asthma and COPD in Sweden. Pharmacoepidemiol Drug Safe 2008, 17(5):461-467.

22. Marklund B, Tunsäter A, Bengtsson C: How often is the diagnosis bronchial asthma correct? Fam Pract 1999, 16(2):112-116.

23. Montnemery P, Hansson L, Lanke J, Lindholm LH, Nyberg P, Löfdahl CG, Adelroth E: Accuracy of first diagnosis of asthma in primary health care. Fam Pract 2002, 19(4):365-368.

24. Cuzzolin L, Zaccaron A, Fanos V: Unlicensed and off-label uses of drugs in paediatrics: a review of the literature. Fundam Clin Pharmacol 2003, 17(1):125-131

25. Statistics Sweden: Official statistics of number of inhabitants in Skaraborg in 2005. http://www.scb.se (accessed June 10, 2012).

26. Wirehn AE, Karlsson HM, Carstensen JM: Estimating disease prevalence using a population-based administrative healthcare database. Scand $J$ Public Health 2007, 35(4):424-431.

27. Ställberg $B$, Ehrs $P$ : Vårdnivåer och omhändertagande i primärvården. [Carelevels and management in primary health care.]. Information från Läkemedelsverket 2002, 3:67 [in Swedish].

28. Mainous AG, Zoorob J, Hueston WJ: Current management of acute bronchitis in ambulatory care. Arch Fam Med 1996, 5(2):79-83. 
29. Becker LA, Hom J, Villasis-Keever M, van der Wouden JC: Beta2-agonists for acute bronchitis. Cochrane Database Syst Rev 2011, 7:CD001726.

30. Ufer M, Kimland E, Bergman U: Adverse reactions and off-label prescribing for paediatric outpatients: a one-year survey of spontaneous reports in Sweden. Pharmacoepiemiol Drug Saf 2004, 13(3):147-152

31. Han MK, Kim MG, Mardon R, Renner P, Sullivan S, Diette GB, Martinez FJ: Spirometry Utilization for COPD: How Do We Measure Up? Chest 2007, 132:403-409.

32. Lange P, Rasmussen FV, Borgeskov $H$, Dollerup J, Jensen MS, Roslind K, Nielsen LM, KVASIMODO study Group: The quality of COPD care in general practice in Denmark: the KVASIMODO Study. Prim Care Respir J 2007, 16:174-181.

33. Thorn J, Norrhall M, Larsson R, Curiac D, Axelsson G, Ammon C, Månsson J, Brisman J, Söderström AL, Björkelund C: Management of chronic obstructive disease (COPD) in primary care: a questionnaire survey in western Sweden. Prim Care Respir 2008, 17:26-31.

34. Pont $L G$, van der Werf GT, Denig P, Haaijer-Ruskamp FM: Identifying general practice patients diagnosed with asthma and their exacerbation episodes from prescribing data. Eur J Clin Pharmacol 2002, 57(11):819-825.

doi:10.1186/1471-2296-15-54

Cite this article as: Weidinger et al: Medication prescribing for asthma and COPD: a register-based cross-sectional study in Swedish primary care. BMC Family Practice 2014 15:54.

\section{Submit your next manuscript to BioMed Central and take full advantage of:}

- Convenient online submission

- Thorough peer review

- No space constraints or color figure charges

- Immediate publication on acceptance

- Inclusion in PubMed, CAS, Scopus and Google Scholar

- Research which is freely available for redistribution 